\title{
A spatio-temporal analysis of fires in South Africa
}

AUTHORS:

Sheldon Strydom ${ }^{1}$ iD

Michael J. Savage ${ }^{1}$ iD

\section{AFFILIATION:}

${ }^{1}$ School of Agricultural, Earth and Environmental Sciences, University of KwaZulu-Natal,

Pietermaritzburg, South Africa

\section{CORRESPONDENCE TO:}

Michael J. Savage

EMAIL:

savage@ukzn.ac.za

\section{DATES:}

Received: 21 Dec. 2015

Revised: 21 June 2016

Accepted: 09 Aug. 2016

\section{KEYWORDS:}

climate change; fire frequency; mitigation and monitoring;

MODIS; wildfires

\section{HOW TO CITE:}

Strydom S, Savage MJ. A spatio-temporal analysis of fires in South Africa. S Afr J Sci. 2016;112(11/12), Art. \#2015-0489, 8 pages. http://dx.doi.org/10.17159/ sajs.2016/20150489

\section{ARTICLE INCLUDES: \\ $\checkmark$ Supplementary material \\ $\times$ Data set}

FUNDING:

National Research Foundation (South Africa)

(c) 2016. The Author(s). Published under a Creative Commons Attribution Licence.
The prevalence and history of fires in Africa has led to the continent being named 'the fire continent'. Fires are common on the continent and lead to a high number of annual fire disasters which result in many human fatalities and considerable financial loss. Increased population growth and concentrated settlement planning increase the probability of fire disasters and the associated loss of human life and financial loss when disasters occur. In order to better understand the spatial and temporal variations and characteristics of fires in South Africa, an 11-year data set of MODIS-derived Active Fire Hotspots was analysed using an open source geographic information system. The study included the mapping of national fire frequency over the 11-year period. Results indicate that the highest fire frequency occurred in the northeastern regions of South Africa, in particular the mountainous regions of KwaZulu-Natal and Mpumalanga, and in the Western Cape. Increasing trends in provincial fire frequency were observed in eight of the nine provinces of South Africa, with Mpumalanga the only province for which a decrease in annual fire frequency was observed. Temporally, fires were observed in all months for all provinces, although distinct fire seasons were observed and were largely driven by rainfall seasons. The southwestern regions of South Africa (winter-rainfall regions) experienced higher fire frequencies during the summer months and the rest of the country (summer-rainfall regions) during the winter months. Certain regions - those which experienced bimodal rainfall seasons - did not display distinct fire seasons because of the complex wet and dry seasons. Investigation into the likely effects of climate change on South African fire frequency revealed that increased air temperatures and events such as La Niña have a marked effect on fire activity.

\section{Significance:}

- $\quad$ Fires have played a significant role in the morphology of the African continent.

- $\quad$ Fires provide a number of environmental services.

- $\quad$ Fires were observed in all months in all provinces in South Africa, although distinct fire seasons were observed and were largely driven by rainfall seasons.

- Global climate change will result in an increase in the frequency of fires.

\section{Introduction}

The African continent has for years been termed 'the fire continent' as a result of the high number of fires it experiences. ${ }^{1}$ The development of advanced remote-sensing technologies has allowed the study of fires at a greater spatial resolution, in the context of vegetation communities and topography, and, more recently, in the context of climate change. ${ }^{1}$ Remote sensing has also allowed for the study of fires over larger regions compared to the highly localised research areas such as the Kruger National Park and other national parks.

\section{Fires in South Africa}

Fire has always and will always be a natural and important phenomenon in environmental systems. However, because of an increase brought on through anthropogenic activities, fires are having a negative impact on the environment and more so on society and the economy. The likelihood of an 'accident' fulfilling the requirements to be classified as a disaster is increasing as a result of increased population densities and increased settlement in high-risk areas. ${ }^{2}$ Fire disasters are of great concern in South Africa and one can conclude that these disasters are going to increase. ${ }^{2} \mathrm{~A}$ large percentage of South Africa's population is located in rural areas, where they often are housed in close quarters, which allows fires to spread rapidly through housing structures. These rural areas are also generally situated in fire-prone regions of the country, making them vulnerable to fires.

A total of about 35000 fires was reported during the 2008 fire season in South Africa, with a majority of fires originating from open flames during waste, grass or bush burnings; these fires led to close to 380 fatalities and more than ZAR2.3 billion in financial losses. ${ }^{3}$ During the 2009 fire season, more than 40000 fires were reported, and resulted in 376 fatalities and ZAR4 billion in financial loss - again with open flames during waste, grass or bush burnings identified as the source of most of the fires. ${ }^{4}$ The 2010 fire season experienced similar statistics with a high number of fatalities caused by fires and a large financial loss. ${ }^{5}$ These statistics clearly indicate the potential of fires to result in both loss of life and financial loss. The South African National Veld and Forest Fire Act of 1998 (Act 101 of 1998) specifies the prevention of wildfires through the implementation of a National Fire Danger Rating System under the responsibility of the Department of Water Affairs and Forestry. The National Fire Danger Rating System is currently operational and is being used by the South African Weather Service and other interested parties to mitigate wildfire outbreaks. Under the Act, fire prevention is considered the responsibility of the landowner and lack of regional coordination is visible. ${ }^{6}$ While regional coordination is lacking, a number of regional fire prevention or protection agencies has been established. These agencies comprise mostly private landowners and agro-forestry managers working as 'umbrella' fire protection associations. ${ }^{6}$ The National Veld and Forest Fire Act of 1998 promotes the formation of these regional fire protection associations and requires all landowners to be members of local fire protection associations but coordination between different fire protection associations is minimal. ${ }^{7}$ 


\section{Adverse effects of fires}

Fire is associated with atmospheric pollution largely because of the release of carbon monoxide and ozone during biomass burning as well as emission of carbon dioxide. ${ }^{8}$ Smoke haze has been linked to human respiratory diseases and poses a concern for agricultural crop productivity. The burning of biomass attributed to wildfires has a direct impact on climate change. Burning of biomass releases high concentrations of oxocarbons which act as a greenhouse gas by absorbing and re-emitting infrared radiation. ${ }^{9}$ Black carbon has also been linked to positive feedback mechanisms when deposited on surfaces such as snow where it alters the surface radiation balance and hence the energy balance. Altering the surface radiation balance leads to a warmer temperature on the snow surface which leads to snowmelt which further exposes darker surfaces, leading to further warming. ${ }^{9} \mathrm{It}$ is acknowledged that fire is a necessity when used as a land surface management tool. However, by identifying areas prone to wildfires, one may, at the same time, identify areas that contribute significantly to atmospheric pollution and focus mitigation resources on these identified areas. Of concern is when a highly populated area experiences high fire frequencies, as the byproducts of the fires may adversely affect those populations.

Fire also has the ability to enhance or increase soil erosion. Particularly severe fires have been shown to remove surface vegetation and influence soil organic material and peat. This loss of vegetation effectively decreases the surface's ability to infiltrate surface runoff after a precipitation event. 10,11 Increased surface runoff then results in increased soil removal, but may also result in flash floods or increased sedimentation of water systems. Soil erosion may be exacerbated by fire activity when the area has already been overgrazed. Fires on mountain slopes have been shown to decrease infiltration by as much as $50 \%$, thereby increasing the catchment's risk of flash flooding. ${ }^{11}$ Much of South Africa is vulnerable to severe land degradation because of improper agricultural practices such as overgrazing. ${ }^{10,12}$ Degradation in already vulnerable areas may be exacerbated through increased fire activity. For a province like the Eastern Cape, which is notorious for its severe soil erosion, further degradation could be mitigated or limited by identifying areas prone to fires and assessing the role of fires in removing land cover in those areas. Mountainous regions may also be vulnerable because of the steepness of slopes and the high fire frequencies associated with Berg winds. By identifying these areas, managers may be able to combat further degradation by limiting fire activity and ensuring the prevention of uncontrollable fires.

\section{Need for a detailed spatio-temporal analysis of South African fires}

Despite progress in fire mitigation and management, the country still experiences many fire disasters annually. Previous research has focused on the spatio-temporal characteristics of fires in protected areas which cannot be extrapolated to the rest of the country with reasonable accuracy. ${ }^{1}$ A study of the spatio-temporal characteristics of South African fires is lacking, with only a few local studies having been published. ${ }^{1,13,14}$ The mapping of areas prone to hazards is a common practice in disaster management and aids in identifying 'at risk' areas as well as providing insight to the spatial and temporal changes of natural hazards. A detailed spatio-temporal study can be used to identify areas within the country that are prone to fire activity and to identify times when fire activity is at its highest, with temporal scales ranging from months to years.

\section{Motivation for the study}

Fire has played a significant role in shaping the African landscape. Fires do indeed provide a number of environmental services, but increased anthropogenic fire activity may result in adverse effects such as loss of human life and property, enhanced environmental degradation and increased greenhouse gas concentrations. In order to mitigate the loss of human life and other adverse effects of wildfires, a spatio-temporal analysis of South African fires was undertaken to provide landowners and critical decision-makers with a better insight into the temporal and spatial variations of fires in South Africa.

\section{Methodology}

\section{Data acquisition}

One of the challenges faced when initiating the study was the lack of a national database of fires listing times and locations of fires. As no data set was available from government or independent research groups, it was decided to acquire raw data through the US National Aeronautics and Space Administration's (NASA) Earth Observing System Data and Information System (EOSDIS). The EOSDIS allows a registered user to download data in a specified format for a specified area during a user selected time frame.

\section{Data characteristics}

Archived fire data were accessed through NASA's Fire Information for Resource Management System (FIRMS). Based at the University of Maryland, FIRMS distributes fire hotspot information to a number of countries. ${ }^{15}$ FIRMS data are obtained from the Moderate Resolution Imagining Spectrometer (MODIS) instruments aboard NASA Rapid Response satellites. ${ }^{15}$ FIRMS incorporates remote sensing and geographic information system (GIS) technologies to produce MODIS fire data. MODIS fire data are provided in three unique ways: through an online mapping interface, through customised email alerts and through text messaging. ${ }^{16}$ For this study, only Active Fire Data were used. The Active Fire product contains contextual algorithms which use data obtained from the mid-infrared (3.929-3.989 $\mu \mathrm{m})$ and thermal infrared $(10.780-11.280 \mu \mathrm{m})$ wavelengths as well as a 'fire radiative power parameter'. Products are generated daily at full resolution and plotted to $0.5^{\circ}$ grids. ${ }^{16}$

Because the time span of the data set needed exceeded 8 days, archived data were needed. Using the EOSDIS Archive Data Tool, a polygon was inserted surrounding the area of interest - in this case South Africa. In order to select the entire South African land surface, a polygon larger than South Africa was drawn. Once an area of interest was selected, the calendar tool was used to select a time frame of 11 years, spaning from 1 January 2003 to 31 December 2013.

\section{Limitations}

As stated previously, one of the main challenges was acquiring a database containing national fire point locations with a temporal analysis. Reaching out to government departments and private research institutes proved fruitless; a database was therefore acquired through NASA's EOSDIS. Validation of archived remote-sensing data is a known challenge. Ground truthing or validation of fires detected by the MODIS satellites as far back as 2003 is impossible - which raises questions on the accuracy of the data used. A number of methods exist to validate satellite-derived fire products. ${ }^{15}$ These methods require extensive field work shortly after the detection of a fire - essentially pointless when a data set is older than a few weeks. While ground truth validation was not possible in this study, the Active Fire product was validated using sample locations representative of the general area's vegetation, i.e. hotspots detected in South Africa were validated using a tropical savanna/grassland biome to mask out hotspots created by water bodies, mines and power stations. ${ }^{16}$

\section{Data processing}

Data were downloaded using the EOSDIS Archive Download Tool. For convenience, a shapefile format was selected to display the total number of fires detected within the area of interest between 2003 and 2013. The shapefile included an attribute table with information regarding time of detection, date of detection, location of hotspot, brightness of hotspot as well as a confidence level. The shapefile containing vector points of hotspots was projected in QGIS ${ }^{\circledR}$ using the Hartebeeshoek94 coordinate reference system. All shapefiles added thereafter to QGIS were projected using the Hartebeeshoek94 coordinate reference system to ensure spatial accuracy. The total hotspot shapefile was clipped to the borders of South Africa, eliminating any detected hotspots that were not within South Africa. To ensure the study focused on hotspots created by fires, only points with a confidence level of $100 \%$ were selected for analysis. 
Analysing national fire distribution required the attribute table of $100 \%$ confidence level fires to be exported to Microsoft Excel, in which both univariate and bivariate descriptive statistics were applied. The QGIS was used to create a map illustrating the total distribution of $100 \%$ confidence level fires in the country between 2003 and 2013 which was overlaid with a shapefile of South African provincial boundaries. A shapefile of vegetation zones was added to the QGIS project to analyse fire distribution as a variable of vegetation. In order to calculate the total number of fires in each vegetation class, the QGIS Spatial Query tool was used. In order to better understand the role of vegetation in fires, the 11-year fire point data set was combined with a 1:50 000 vegetation shapefile which included 67 different vegetation classes. Fire points in each vegetation class were counted. This was done for all vegetation classes and then exported to Microsoft Excel for further investigation. Analysing provincial fire distribution used a similar method. Fire totals per province were calculated using the spatial query tool and then exported to Excel. As the attribute table included time of detection for each fire spot, it was possible to study temporal variations.

It must be noted that although only $100 \%$ confidence level fire points were considered in the study, the study may not have included all actual fires that occurred between 2003 and 2013 as a result of operational errors of the MODIS in which an actual fire may be detected but assigned a confidence level of less than $100 \%$ depending on its brightness and track. Cloud cover during the MODIS overpass may also reduce the number of active fires detected.

\section{Results}

\section{National fire statistics}

Using the 11-year data set of fire points, a map was created to indicate the total distribution of fires in the country per province. Figure 1 gives a clear indication that the northeastern and eastern regions of the country experienced the most frequent fires over the last 10 years. The southwest regions of the country also appear to have a high fire frequency compared to surrounding regions. From Figure 1 it is clear that topography and climate play a role in fire totals as evidenced by the high density of fire points along significant mountain ranges. For example, the main spread of fires in the southwest regions can be associated with the Cape Fold Mountains, while the western border of KwaZulu-Natal experiences a high concentration of fires along the Drakensberg mountain range. The Free State's highest fire concentration is situated along the Lesotho border, which is also part of the northern Drakensberg range. It should be noted that all fires, including those that occurred in close proximity to urban areas, were used in the analysis. Results produced from data excluding fires within a $20-\mathrm{km}$ radius of an urban area can be found in the online supplementary material (Supplementary figure 1).

\section{Vegetation statistics}

As stated earlier, South Africa experiences two different rainfall seasons with some locations experiencing a bimodal rainfall distribution. These different rainfall seasons, associated with summer and winter months, have led to a wide variety of vegetation types in the country. The country's varied topography has also led to different vegetation patterns in mountainous areas, where air temperature and rainfall gradients vary over small areas resulting in pockets of different vegetation. Table 1 provides a list of the 'top ten' vegetation classes. These 10 vegetation types have the highest number of fires over the 11-year period. Table 1 also includes a percentage which indicates the ratio of fires in each vegetation class to the total number of fires.

Mountain grasslands in the northeastern regions of the country experienced the most fires over the 11-year period, followed by mountainous fynbos. The top ten vegetation types can easily be categorised into three main biomes: grassland, bushveld and fynbos. Of note is that while grasslands feature in the top ten, they are mostly associated with upland or mountainous areas such as western and southern KwaZuluNatal or northwestern KwaZulu-Natal rather than the open plains type of grassland associated with the central Free State. The top ten can also be linked to the three provinces which experience high fire frequency. The vegetation types listed in Table 1 contributed to about $60 \%$ of all fires between 2003 and 2013, leaving the remaining 57 vegetation types contributing only $40 \%$, again indicating the high concentration of fires in certain regions of the country.

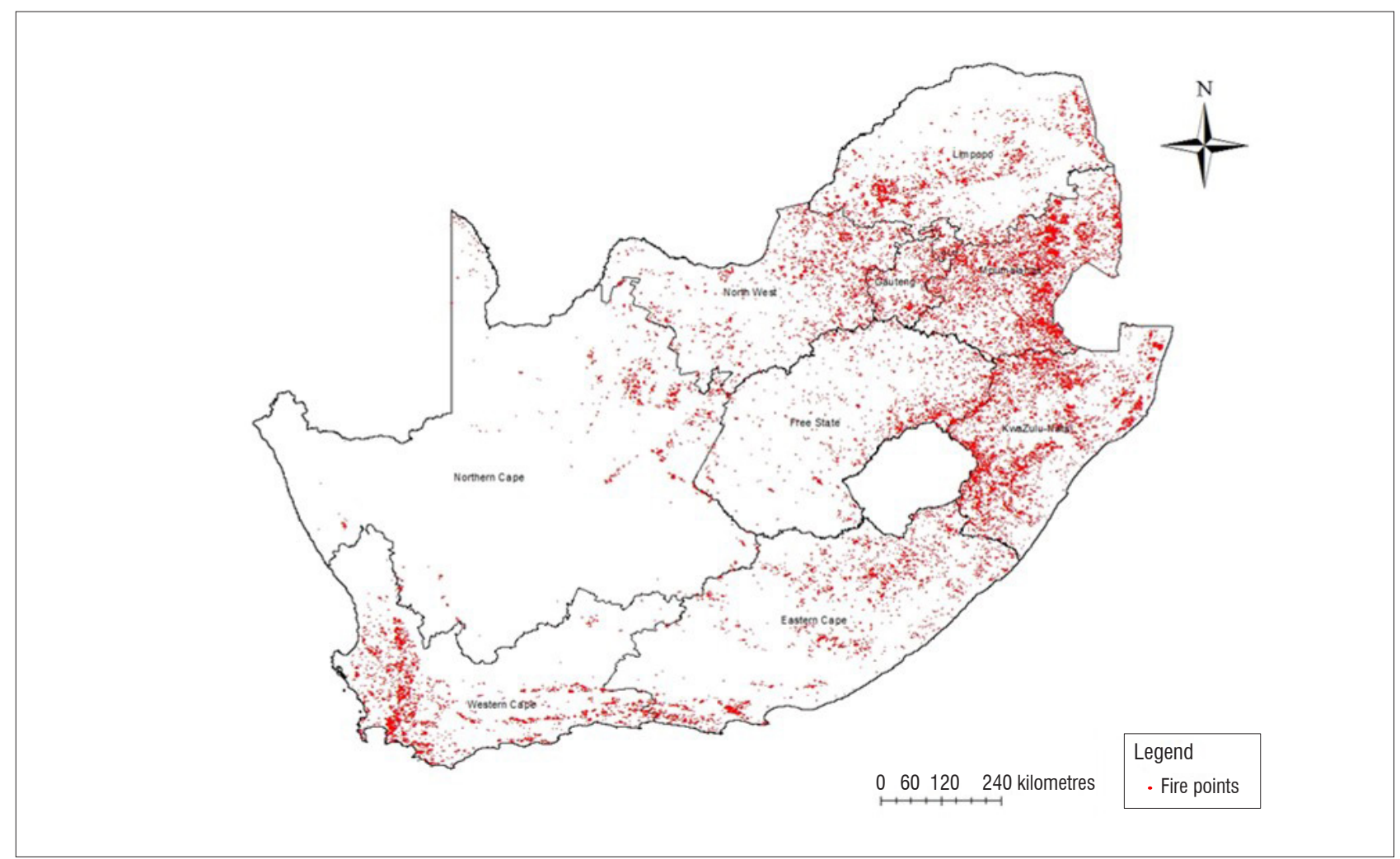

Figure 1: Fire distribution in South Africa between 2003 and 2013. 
Table 1: Total number of fires in South Africa per vegetation class and percentage of total fires for the 11-year period from 2003 to 2013

\begin{tabular}{l|c|c}
\hline \multicolumn{1}{c|}{ Vegetation } & Number of fires & Percentage \\
\hline Northeastern Mountain Grassland & 4513 & 12.71 \\
\hline Mountain Fynbos & 3291 & 9.26 \\
\hline Moist Upland Grassland & 2711 & 7.63 \\
\hline Mixed Bushveld & 2516 & 7.08 \\
\hline Sour Lowveld Bushveld & 1633 & 4.60 \\
\hline Moist Sandy Highveld Grassland & 1598 & 4.50 \\
\hline Rocky Highveld Grassland & 1596 & 4.49 \\
\hline Moist Cool Highveld Grassland & 1228 & 3.46 \\
\hline Natal Central Bushveld & 1225 & 3.45 \\
\hline Wet Cold Highveld Grassland & 1113 & 3.13 \\
\hline
\end{tabular}

\section{Annual fire trends}

Acquiring an 11-year data set made it possible to analyse interannual trends in fire frequency. The effect of climate change on fire frequency is not known despite a number of existing scenarios. Figure 2 illustrates the total number of fires experienced in South Africa between January 2003 and December 2013. While no clear trend is evident in Figure 2 (slope = about 48 fires per annum, $t=0.61$, significant at $44 \%$ confidence level), there appears to be a stabilisation in fire totals over the last 3 years, beginning in 2011 and continuing through 2013. However, 3 years of stabilisation does not mean that fires are being better managed or that mitigation efforts are successful, and further investigation in the upcoming years will be needed to fully understand the trend, assuming the trend, or lack thereof, continues.

Also of note is the higher than average number of fires in the years 2005 , 2007 and 2010. Years 2005 and 2010 have been classified as two of the warmest years in the past decade and the effect of these above-average air temperatures seems to have a strong correlation with fire frequency. The year 2006 has also been classified as the warmest La Niña year in the past decade, which may explain the high fire frequency in 2007.

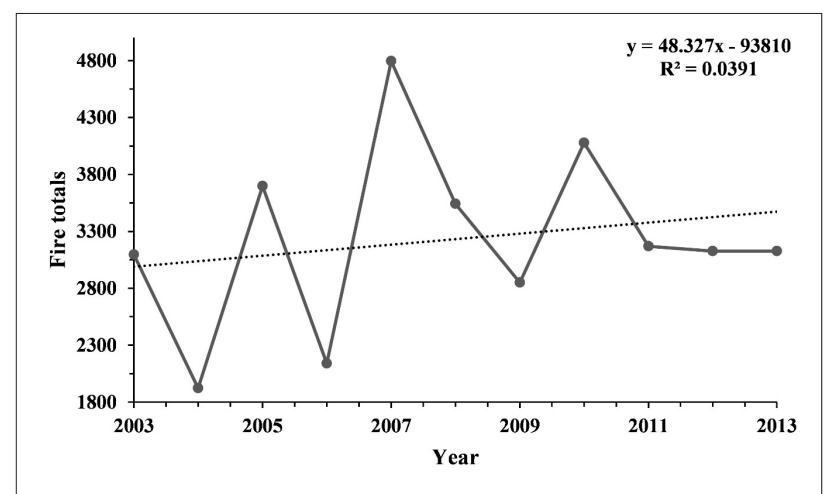

Figure 2: Annual fire totals for South Africa.

\section{Monthly averages}

South Africa is known to experience a number of fire seasons as a result of the variability of the country's rainfall seasons. As the western and southwestern parts of the country receive mainly winter rainfall, their fire season generally occurs in the summer months while the central and eastern portions of the country experience a winter fire season because of their summer rainfall pattern. Totalling the number of fires per month for each year in the data set and producing monthly averages shows which months are prone to fires. Figure 3 illustrates the months which experience the highest number of fires. It is clear that the majority of fires occur in August and September; this finding therefore indicates that the central and eastern regions of the country experience higher fire numbers than the western portions, as August and September fall into the dry winter months in the central and eastern regions and the wet winter months in the west. While the highest fire numbers are seen in August and September, months associated with the western region fire season (December to March) also have relatively high averages.

It is important to note that while the winter fire season may appear to have higher fire frequencies, the size of the area is much larger than that which receives winter rainfall. Areas which receive winter rainfall are also largely semi-arid, thus limiting the fuel available to burn during a fire, which may limit fire activity. August and September can clearly be identified as the most severe months for fire outbreaks but Figure 3 also shows that fires are possible at all times during the year, which serves as a challenge to landowners and critical decision-makers.

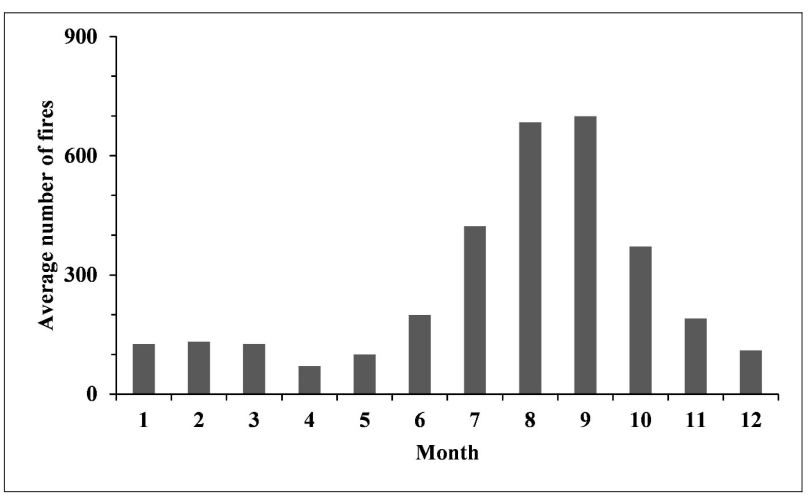

1, January...12, December

Figure 3: $\quad$ Monthly fire averages between 2003 and 2013 for South Africa.

\section{Provincial fire statistics}

The National Veld and Forest Fire Act of 1998 promotes the establishment of regional fire protection association and requires all landowners to be members of a fire protection association. By understanding provincial trends in wildfires, these fire protection associations and landowners may be better equipped to mitigate and manage fire outbreaks in their respective provinces. As each province in South Africa has different topographic and climatic factors, one cannot expect the management plans of each province to be the same and each province needs to develop its own plan according to its own fire season and fire pattern.

\section{Annual trends in provincial fire totals}

Using GIS processing, the total number of fire spots per province was calculated and plotted over time. The calculations included yearly totals as well as monthly average fire numbers (Figure 4). Assessing the trends in yearly fire numbers may provide for better management and better allocation of funds and resources. All provinces display an increasing or stable trend in interannual fire totals, with the exception of the Western Cape which has experienced a small decline in fire totals since 2003. While the trend may be indicating a decrease, there has nevertheless been years in which the Western Cape experienced a significantly high number of fires. It should be noted that only the Northern Cape's annual fire frequency yielded a slope value that was greater than 0 . The Northern Cape Province displayed the most noteworthy increasing trend in fire totals from 2003 (slope $=$ about 16 fires per annum, $t=1.87$, significant at a $90 \%$ confidence level). While some years have fewer fires than the previous years, the overall trend indicates that fires may be becoming a common problem in the province. Other provinces do not display significant increasing trends and the Eastern Cape Province is the only province that appears to have a stable trend in fire totals since 2003 , with an increasing slope of about two fires per annum. Table 2 provides an overview of the slope, $t$-value and confidence level of each province and the South African region as a whole. 


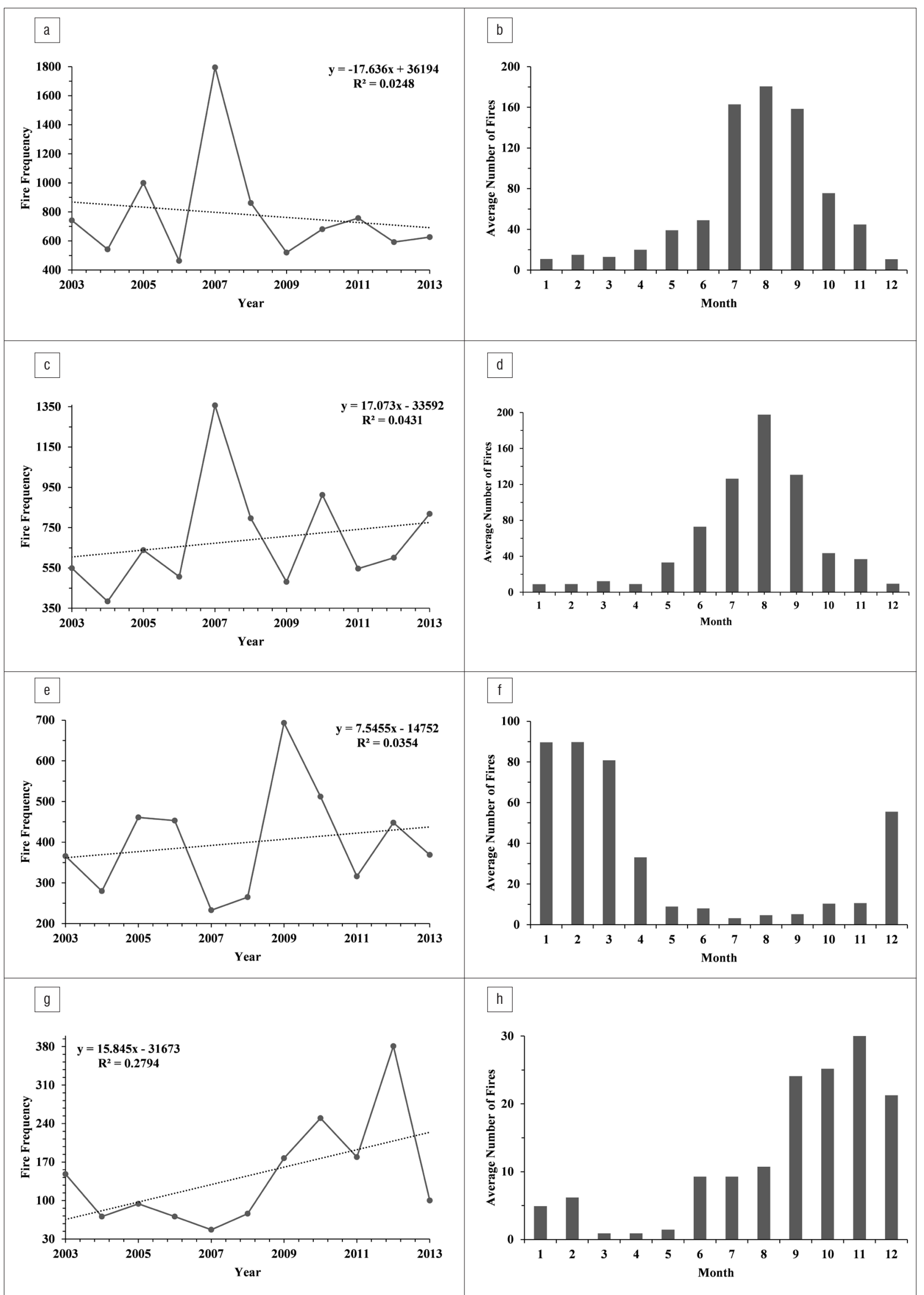

Figure 4: Annual fire totals for selected South African provinces (a, c, e, g represent annual totals and b, d, f, h represent monthly averages): (a and b) Mpumalanga, (c and d) KwaZulu-Natal, (e and f) Western Cape and ( $g$ and $h$ ) Northern Cape. 
Table 2: $\quad$ Statistics for the whole South African region and individual provinces

\begin{tabular}{l|c|c|c|c}
\hline \hline \multicolumn{1}{c|}{ Area } & Slope & $\boldsymbol{R}$ & $\boldsymbol{t}$ & Confidence \\
\hline Northern Cape & 15.85 & 0.53 & 1.87 & 90.54 \\
\hline Free State & 7.70 & 0.26 & 0.80 & 55.84 \\
\hline KwaZulu-Natal & 17.07 & 0.21 & 0.64 & 45.97 \\
\hline South Africa & $\mathbf{4 8 . 3 3}$ & $\mathbf{0 . 2 0}$ & $\mathbf{0 . 6 1}$ & $\mathbf{4 3 . 9 9}$ \\
\hline Limpopo & 8.02 & 0.19 & 0.58 & 42.70 \\
\hline Western Cape & 7.55 & 0.19 & 0.57 & 42.04 \\
\hline North West Province & 6.65 & 0.18 & 0.55 & 40.63 \\
\hline Mpumalanga & -17.64 & -0.16 & -0.48 & 35.62 \\
\hline Gauteng & 1.16 & 0.14 & 0.43 & 32.58 \\
\hline Eastern Cape & 2.05 & 0.04 & 0.12 & 9.30 \\
\hline
\end{tabular}

\section{Provincial variations in fire seasons}

As stated previously, two seasonally distinct regions with characteristic fire seasons exist in the country: the cool, dry winter fire season experienced in the central and eastern regions of the country and the warm, dry summer season experienced in the west and southwest regions of the country. An analysis of provincial peaks in fire frequency, presented in Figure $4 \mathrm{a}-\mathrm{h}$, indicates slightly more discrete fire seasons. Figure 4 also illustrates different peaks in fire seasons around the country. The Western Cape experienced its peak in fire numbers in February, while the Northern Cape experienced a peak in November two different peaks in fire season, although these two provinces both experience winter rainfall and thus a summer fire season. Mpumalanga and KwaZulu-Natal both experienced a peak in fire season in August while the North West Province, Gauteng, Limpopo, the Free State and the Eastern Cape experienced a peak in fire season in September (Supplementary figure 2).

While each province can be categorised into a specific fire season, it is important to note the severity of each province's fire season. Mpumalanga, KwaZulu-Natal and the Western Cape have been identified as the three provinces which experience the most severe fire seasons largely because of their native vegetation, topography and climate. KwaZulu-Natal and Mpumalanga have minimum monthly averages of about 10 fires and a maximum of close to 200 fires at their peak in the fire season. The rest of the provinces display similar minimum averages of close to one fire per month and have maximum averages ranging between 30 fires and 120 fires during the peak in the fire season (Supplementary figure 2).

\section{Discussion}

\section{National distribution of fires}

Figure 1 provides a stark indication of the severity of fire occurrences in South Africa over the last 11 years. The vegetation types which experience the highest frequency of fires occur in the northeastern and eastern regions of the country. Table 1 provides a list of the vegetation types most prone to fires. It is clear that grasslands and bushveld are common fire areas. A number of reasons can be cited for the link between these vegetation types and their high fire frequency. Vegetation such as grasslands and bushveld are able to grow rapidly and densely if provided with sufficient rainfall. When grasslands and bushveld grow, they produce a high fuel load as a result of the high biomass associated with the vegetation. During the dry season, the water content of the vegetation decreases, providing a fuel for fires to ignite and spread. The top ten vegetation types all have characteristics conducive for fires to occur. Many are classified as moist or wet, indicating an association with an above-average rainfall season (either summer or winter rainfall season). Furthermore, many of these vegetation types are classified as mountainous or upland vegetation (the significance of which is discussed below).

Figure 1 also provides an insight into the role of topography in fire occurrences. The importance of topography in fire behaviour and fire likelihood is often overlooked by the South African fire community and is not taken into consideration when monitoring or calculating fire danger using the Lowveld fire danger index, evident by the lack of a fire behaviour model. Fire danger indices used by developed countries, such as the Australian McArthur Forest and Grassland Fire Danger Indices and the US National Fire Danger Rating System, consider topography when monitoring and predicting fire danger. The concentration of fire points along ranges such as the Drakensberg and Cape Fold Mountains indicates the need to account for topography as it has a marked influence on fires. Topography can also lead to dry mountain winds, known as berg winds in South Africa, which have been proven to exacerbate fire danger. Furthermore, it is believed that fires which originate on mountain slopes and spread upslope may be enhanced by the local topography. Under general meteorological conditions, one would assume that anabatic winds prevail during the day, essentially spreading any fire that starts upslope. As a fire moves upslope, the heat emitted causes the surrounding air mass to warm and rise, creating a ventilation system for the fire. The reasons stated above may explain the high concentration of fires along the major ranges of South Africa. Therefore, it is important for landowners, community managers and critical decision-makers to be aware of the topography of their area and assess its role in the local fire dynamics and develop plans accordingly.

\section{Annual fire frequency trends}

The annual fire frequency trends, displayed in Figure 2, are revealing in terms of the impact of predicted climate change and interannual climatic variations on fire. As seen in Figure 2, the years 2005, 2007 and 2010 experienced the greatest number of fires in the last decade. Years 2005 and 2010 have been cited as two of the warmest years on record in the southern hemisphere compared to a global average. ${ }^{17}$ One can assume that South Africa's annual average air temperatures would be similar to that of the southern hemisphere as a whole.

Two possible scenarios have been established for fires under a warming climate. The first scenario states that under warmer air temperatures, heat waves and drought conditions may be more severe, which may result in vegetation desiccating at higher rates, leading to drier fuel loads resulting in increased fire numbers. The second scenario states that under a warming climate, rainfall may be significantly higher. ${ }^{18}$ Higher rainfall totals may lead to increased rates of vegetation growth, leading to heavier fuel loads which results in more available fuel to burn and also increased rates of spread when fires occur. As 2005 and 2010 have been marked as years of above-average air temperature, they serve well to investigate the possible effect of global warming on South Africa's fire frequency. As both years have high fire frequencies, one can assume that the two scenarios are accurate.

While 2007 is not seen as a significantly above-average year in terms of air temperature, it still experienced a high fire count. However, 2006 has been cited as one of the warmest La Niña events. La Niña results in increased rainfall over the eastern half of South Africa. As 2006 has been cited as the warmest La Niña event, one can also assume that air temperatures were greater than average. Increased air temperatures and increased rainfall may have led to increased vegetation growth, which during the 2007 winter (the eastern region's fire season) - could have resulted in higher fire frequencies which would be in agreement with the first possible scenario for fires under global warming. The South African Weather Service has made seasonal rainfall charts available (Figure 5). Analysis of these charts confirms that higher than normal rainfall, indicative of a La Niña event, occurred during the summer rainfall season between 2006 and 2007, which may explain the increased fire activity during the 2007 fire seasons. Despite other explanations as to why 2007 experienced the greatest fire totals, it is clear that global climate change will result in increased fires, which needs to be taken into consideration by government, landowners and fire protection associations. 


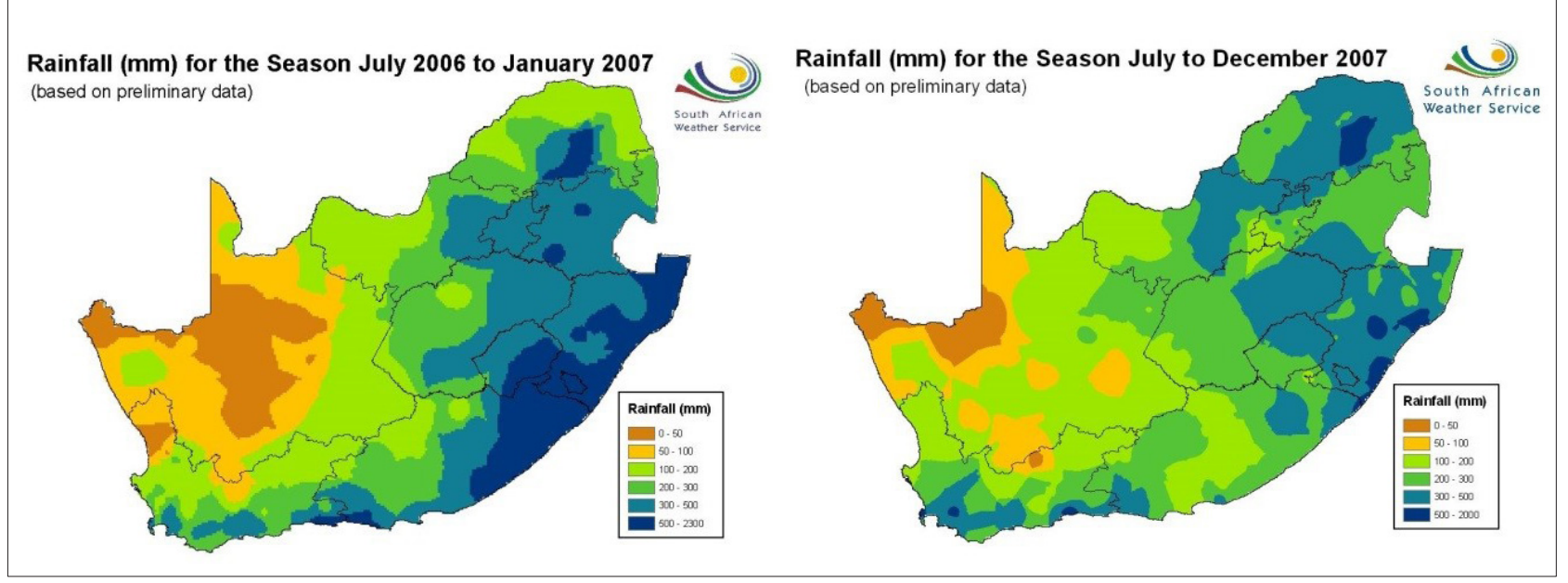

Charts courtesy of the South African Weather Service.

Figure 5: Seasonal rainfall prior to and during the 2007 fire seasons with (a) indicating the high rainfall totals experienced between July 2006 and January 2007 and (b) showing the total rainfall experienced between July and December 2007.

\section{Provincial distribution of fires}

Traditionally, two main fire seasons have been noted: the winter fire season of the eastern regions and the summer fire season of the western regions. The variation in fire seasons across the country is largely because of climatic conditions. As evident in the monthly distribution of fires for the various provinces, shown in Figure 4, there are four main peaks in fire seasons:

- Mpumalanga and KwaZulu-Natal, both situated in the far eastern regions of the country, experience a maximum in fire activity during August.

- The Western Cape on the southwestern seaboard experiences a maximum in February.

- The maxima of these three provinces have traditionally been identified as the peak of the two main fire seasons.

- Other provinces such as the North West Province, Free State, Gauteng and Eastern Cape experience maxima in September and the Northern Cape in November.

While these four distinct peaks occur in the conventional fire seasons, it is still important for landowners and decision-makers to take note of the months in which fire activity is at a maximum in their respective provinces so as to ensure the correct timing of resources, and to ensure the efficient provision of resources and infrastructure.

\section{Annual trends in provincial fire activity}

It is clear that while increasing and decreasing trends exist (as indicated by the slope), these trends are not statistically significant when using traditional significance levels. It is hypothesised, however, that the limited annual duration of the data sets $(n=11)$ may have reduced the significance of the trends. The fact that fire numbers are influenced by anthropogenic activity may also have introduced fluctuations in the data set, essentially reducing the statistical significance of the slope relative to 0 .

As previously stated, all provinces (with the exception of Mpumalanga) displayed a stable or increasing trend in fire activity between 2003 and 2013. As seen in Figure 1, Mpumalanga has displayed a high incidence of fire activity over the past 11 years, despite the decreasing trend and has been identified as the province most prone to fire activity. The decline in Mpumalanga's fire activity since 2008 may be, in part, a result of increased awareness of the dangers of fires and the better management and mitigation of fires by local fire protection associations under the Mpumalanga Umbrella Fire Protection Agency.
The Northern Cape Province has experienced the most notable increase in fire activity since 2008. An increase in fire activity in the Northern Cape came as a surprise as the province is largely classified as semiarid with mainly succulent Karoo vegetation. ${ }^{19}$ Provinces surrounding the Northern Cape have also experienced some kind of increase in fire activity over the last 11 years. As noted before, a data set with a time span of 11 years may not be sufficient to draw viable conclusions, but these increasing trends do provide relevant questions.

In the early 1950s, Acocks hypothesised the spread of desertification and land degradation from the southwest into the northeastern regions of the country. ${ }^{12}$ Acocks believed that the grasslands of South Africa were under threat of incremental, progressive and irreversible degradation as a consequence of the spread of deserts coupled with the impact of human over-utilisation of grasslands. ${ }^{12}$ The spread of semi-arid vegetation into grasslands has been theorised to occur along a front or boundary spreading northeast or to occur as a result of the coalescence of degraded patches..$^{19}$ If Acock's theory was true, then the succulent vegetation of the semi-arid Karoo should have invaded the productive grasslands of the northeastern provinces surrounding the Karoo region (namely the Free State and the North West Province). These two provinces, along with the Northern Cape, have however experienced increases in fire activity over the last 11 years. The succulent Karoo vegetation is believed to be less prone to fire than that of grasslands. The spread of semi-arid regions may have resulted in mixed vegetation communities in which both short grasses and the longer Nama Karoo grasses co-exist, which may result in higher fuel loads. A recent study, however, indicates that grasslands have encroached into the semi-arid Karoo landscapes, ${ }^{20}$ which may explain the increased fire activity in the Karoo regions. As stated, increased human settlement in these regions may have led to increased agricultural activity, which is known to alter vegetation structures for livestock grazing. ${ }^{2}$ Agriculture also brings with it the use of fire as a management tool, which may explain the increasing trend. The increases in fire activity may also be brought about by shortterm variability in climate, such as La Niña or El Niño. The spread of semi-arid regions and the effects on fire activity will require further investigation in the future to assess the role of both climate change and human activity on fire activity.

\section{Conclusions}

Fire has always been a natural occurrence on the African continent and has led to the continent being nicknamed 'the fire continent'. Fires do provide an environmental service and are an integral part in the maintenance of the environment; but increased fire activity, brought about by anthropogenic activity, has led to adverse effects in the environment. Fires can be classified as South Africa's most common 
hazard and have often led to disasters which result in both loss of human and animal life and loss of property. The study reported here provides an insight into the spatial (including topography) and temporal distribution of fires in South Africa over the past 11 years and the results indicate that the eastern and northeastern regions of the country are most prone to fires. Fire totals appear to be stabilising despite increased fire activity in certain provinces. The role of climate change and short-term climate variability has been analysed, and increased air temperatures and events such as La Niña have a marked effect on fire activity. In order for fire disasters to be mitigated, landowners and decision-makers need to ensure an efficient and effective allocation of resources, including human resources, to limit the spread of fires and to ensure that fire as a management tool does not result in adverse effects on the environment and society. The results provided here make it possible to identify highrisk areas. In order for the country to be resilient against fire disasters, we need to better understand the spatial and temporal characteristics of our fire seasons. This study has made way for further investigation into the spatio-temporal characteristics of South African fires.

\section{Acknowledgements}

Funding from the National Research Foundation of South Africa to M.J.S. is acknowledged.

\section{Authors' contributions}

S.S. was responsible for conceptualisation of the study, for writing the manuscript and undertaking the data analysis; M.J.S. was the supervisor, assisted with statistical analysis and made conceptual and editing contributions.

\section{References}

1. Archibald S, Nickless A, Govender N, Scholes RJ, Lehsten V. Climate and the inter-annual variability of fire in southern Africa: A meta-analysis using longterm field data and satellite-derived burnt area data. Global Ecol Biogeogr. 2010;19:794-809. http://dx.doi.org/10.1111/j.1466-8238.2010.00568.x

2. Arturson G. Fire disaster management. In: Masellis M, Gunn SWA, editors. The management of burns and fire disasters: Perspectives. Dordrecht: Springer; 2000. p. 53-56.

3. Fire Protection Association of South Africa. 2008 Statistics: Loss ratio poor against the national income [document on the Internet]. c2008 [updated 2010; cited 2013 Feb 25]. Available from: http://www.fpasa.co.za/images/ FireStats/Fire_Stats_2008.pdf

4. Fire Protection Association of South Africa. South African national fire statistics 2009 [document on the Internet]. c2009 [updated $2011 \mathrm{Mar}$; cited 2013 Feb 25]. Available from: http://www.fpasa.co.za/images/FireStats/ Fire_Stats_2009.pdf.

5. Fire Protection Association of South Africa. 2010 South Africa national fire losses [document on the Internet]. c2010 [updated 2012 Mar; cited 2013 Feb 25]. Available from: http://www.fpasa.co.za/images/FireStats/Fire_ Stats_2010.pdf.
6. De Ronde C, Goldammer JG. Fire situation in South Africa: Fire environment, fire regimes, ecological role of fire. International Forest Fire News. 2001;25:105-111.

7. Working on Fire (WOF). Cape burns [media release on the Internet]. 2014 February 6 [cited 2015 Nov 25]. Available from: www.workingonfire.org/ images/WoF_Media_Release_Cape_Burns.pdf.

8. Duncan B, Kangmann B, Textor C, Trentmann J, Van der Werf GR. Vegetation fire emissions and their impact on air pollution and climate. Atmos Environ. 2009;43:107-116. http://dx.doi.org/10.1016/j.atmosenv.2008.09.047

9. Keywood M, Kanakidou M, Stohl A, Dentener F, Grassi G, Meyer CP, et al Fire in the air: Biomass burning impacts in a changing climate. Crit Rev Env Sci Tec. 2013;43:40-83. http://dx.doi.org/10.1080/10643389.2011.604248

10. Townsend SA, Douglas MM. The effect of three fire regimes on stream water quality, water yield and export coefficients in a tropical savanna (northern Australia). J Hydrol. 2000;229:118-137. http://dx.doi.org/10.1016/S00221694(00)00165-7

11. Merz SK. Impacts of bushfires on flood hydrology and erosion rates. Victoria, Australia: Department of Sustainability and Environment; 2004.

12. Meadows ME, Hoffman MT. The nature, extent and causes of land degradation in South Africa: Legacy of the past, lessons for the future? Area. 2002;34:428-437. http://dx.doi.org/10.1111/1475-4762.00100

13. Van Wilgen BW, Biggs HC, Potgieter ALF. Fire management and research in the Kruger National Park, with suggestions on the detection of thresholds of potential concern. Koedoe. 1998;41(1):69-87. http://dx.doi.org/10.4102/ koedoe.v41i1.248

14. Van Wilgen BW. The evolution of fire and invasive alien plant management practices in fynbos. S Afr J Sci. 2009;105:335-342.

15. Tanpipat V, Honda K, Nuchaiya P. MODIS hotspot validation over Thailand. Remote Sens. 2009;1:1043-1054. http://dx.doi.org/10.3390/rs1041043

16. Justice CO, Giglio L, Roy D, Boschetti L, Csiszar I, Davies D, et al. Chapter 29 - MODIS-derived global fire products. In: Ramachandran B, Justice CO, Abrams MJ, editors. Land remote sensing and global environmental change. New York: Springer; 2011; p. 661-679.

17. National Oceanic and Atmospheric Administration (NOAA). Climate at a glance. National Climate Data Centre. No date [cited 2014 Sep 11]. Available from: http://www.ncdc.noaa.gov/cag/time-series/global

18. Intergovernmental Panel on Climate Change (IPCC). Summary for policy makers. In: Climate change 2014: Impacts, adaptions, and vulnerability. Part A: Global and sectoral aspects. Contribution of Working Group II to the Fifth Assessment Report of the IPCC. Cambridge, UK: Cambridge University Press; 2014. p. 1-32. http://dx.doi.org/10.1017/CB09781107415416.005

19. Dean WRJ, Hoffman MT, Meadows ME, Milton SJ. Desertification in the semi-arid Karoo, South Africa: Review and reassessments. J Arid Environ. 1995;30:247-264. http://dx.doi.org/10.1016/S0140-1963(05)80001-1

20. Masubelele ML, Hoffman MT, Bond WJ, Gambiza J. A 50 year study shows grass cover has increased in shrublands of semi-arid South Africa. J Arid Environ. 2014;104:43-51. http://dx.doi.org/10.1016/j.jaridenv.2014.01.011 